double root and consequently the line is tangent to the surface $f=0$. Thus all the lines which belong to the double factor of $\Phi$ are tangent to the surface $f=0$.

Now let the $x_{i}$ and $y_{i}$ have such values that they satisfy $\Phi=0$ but the point $x_{i}$ does not necessarily lie on $f=0$, and consider the totality of lines $v_{i}=x_{i}+y_{i} \tau$ which are tangent to $f=0$. They are given by the equations

$$
f\left(x_{i}+y_{i} \tau\right)=0, \quad \frac{\partial}{\partial \tau} f\left(x_{i}+y_{i} \tau\right)=0 .
$$

The $\tau$-eliminant of equations (12) represents the totality of lines tangent to $f=0$. Hence it includes the two or more factors of $\Phi$ which become equal when the $x_{i}$ satisfy $f=0$. Since the eliminant is rational and $\Phi$ is irreducible, the eliminant must be $\Phi$ itself or a multiple of it.

In the astronomical problem the equation $F=0$ which defines the roots $s_{j}$ is known. The surfaces $f=0$ are therefore readily determined and all possible functions $\Phi$ can be found. To satisfy the conditions which Bruns has stated, $\Phi$ must be factorable into real factors which are polynomials in the $y_{i}$ and rational in the $x_{i}$ and $s$. It is found upon examination that there does not exist a $\Phi$ which satisfies all these conditions and consequently the original $\varphi_{0}$ with which we set out cannot contain $s$. Therefore Bruns' conclusion that we need consider only integrals of the type (2) was correct, even though his argument was wrong. The integrity of the theorem has been preserved by the penetrating insight of Poincaré.

University of Chicago, January 8, 1913.

\title{
NOTE ON THE GROUPS FOR TRIPLE-SYSTEMS.
}

BY MISS L. D. CUMMINGS.

THE method of "Triple-systems as transformations and their paths among triads," given by Professor White in the Transactions, volume 14 (1913), page 6, has been applied by me to the two following triple-systems on fifteen elements. The results obtained agree with the fact, which I had discovered previously by a different method of analysis, that two non-congruent triple-systems may have the same group. 
I.

$\begin{array}{rrrrrr}1 & 2 & 3 & 1 & 8 & 9 \\ 1 & 4 & 14 & 1 & 10 & 15 \\ 1 & 5 & 13 & 2 & 4 & 13 \\ 1 & 6 & 11 & 2 & 5 & 7 \\ 1 & 7 & 12 & 2 & 6 & 10\end{array}$

$\begin{array}{rrr}2 & 8 & 12 \\ 2 & 9 & 15 \\ 2 & 11 & 14 \\ 3 & 4 & 5 \\ 3 & 6 & 7\end{array}$

\section{$\begin{array}{lll}3 & 8 & 15\end{array}$}

$\begin{array}{lll}3 & 9 & 12\end{array}$

$\begin{array}{rrr}3 & 10 & 14\end{array}$

$\begin{array}{lll}3 & 11 & 13\end{array}$

4715

$\begin{array}{lll}4 & 9 & 11\end{array}$

$\begin{array}{lll}4 & 10 & 12\end{array}$

$\begin{array}{lrrrrr}4 & 6 & 8 & 5 & 8 & 11\end{array}$

$\begin{array}{lll}5 & 9 & 10\end{array}$

$\begin{array}{lll}5 & 12 & 14\end{array}$

$\begin{array}{lrr}6 & 9 & 14\end{array}$

61213

$\begin{array}{lll}7 & 10 & 11\end{array}$

$\begin{array}{lll}7 & 8 & 14\end{array}$

$\begin{array}{lll}7 & 9 & 13\end{array}$

$\begin{array}{lll}8 & 10 & 13\end{array}$

$11 \quad 1215$

II.

$\begin{array}{rrrrrr}1 & 2 & 5 & 1 & 9 & 13 \\ 1 & 3 & 8 & 1 & 11 & 12 \\ 1 & 4 & 15 & 2 & 3 & 9 \\ 1 & 6 & 14 & 2 & 4 & 12 \\ 1 & 7 & 10 & 2 & 6 & 10\end{array}$

$\begin{array}{rrr}2 & 7 & 14 \\ 2 & 8 & 13 \\ 2 & 11 & 15 \\ 3 & 4 & 7 \\ 3 & 5 & 10\end{array}$

$\begin{array}{lll}3 & 6 & 15\end{array}$

$\begin{array}{lll}3 & 11 & 13\end{array}$

$\begin{array}{lll}3 & 12 & 14\end{array}$

$\begin{array}{rrr}4 & 5 & 9\end{array}$

$\begin{array}{rrr}4 & 8 & 10 \\ 4 & 11 & 14 \\ 5 & 6 & 11 \\ 5 & 7 & 12 \\ 5 & 8 & 15\end{array}$

$\begin{array}{lll}5 & 13 & 14\end{array}$

$\begin{array}{lrr}6 & 7 & 9\end{array}$

$\begin{array}{lll}6 & 8 & 12\end{array}$

$\begin{array}{lll}13 & 14 & 15\end{array}$

The group for each of the above triple-systems is of order 3 and is generated by the substitution

$$
s=(17 \text { 14) (2 } 6 \text { 10) (3) (4 12 8) (5 } 9 \text { 15) (11) (13). }
$$

February, 1913.

\section{DE SÉGUIER'S THEORY OF SUBSTITUTION GROUPS.}

Théorie des Groupes finis. Eléments de la Théorie des Groupes de Substitutions. Par J. A. DE SÉGuIER. Paris, GauthierVillars, 1912. $\mathrm{x}+228 \mathrm{pp} .10 \mathrm{Fr}$.

ThE earliest separate book on the theory of groups is Jordan's Traité des Substitutions, which appeared in 1870 and is still one of the most valuable treatises along certain lines. Twelve years later there appeared Netto's Substitutionentheorie, which was translated into Italian by G. Battaglini, in 1885, and into English by F. N. Cole, in 1892. Five years after this English translation, W. Burnside published the first separate treatise on groups originally written in our language, under the title Theory of Groups of Finite Order. A second and enlarged edition of this work appeared in 1911. In 1900 the first printed edition of a book on this subject originally written in Italian appeared under the title Lezioni sulla Teoria dei Gruppi di Sostituzioni, by L. Bianchi.

Since the beginning of the present century new books on the theory of groups of finite order have appeared more rapidly, as may be seen from the following list: L. E. Dickson, Linear Groups, 1901; J. A. de Séguier, Groupes abstraits, 1904; H. Hilton, Introduction to the Theory of Groups of Finite Order, 1908; E. Netto, Gruppen und Substitutionentheorie, 1908; 